\title{
Las reflexiones de Diderot en la voz ENCYCLOPÉDIE. Crítica y representación en el diccionario francés
}

\author{
Esteban Ponce $^{1}$
}

Resumen: El propósito de este trabajo es ofrecer una interpretación de algunas reflexiones que realiza Diderot en el artículo ENCYCLOPÉDIE del diccionario homónimo, y que están relacionadas, en su mayor parte, con el problema del paso del tiempo y su repercusión en el diseño de la obra. En particular, me interesa vincular esta problemática con un asunto más complejo y siempre presente en las consideraciones de nuestro autor: el de la potencia crítica de la Encyclopédie y la manera en que ésta podía servir como vehículo de los intereses ilustrados. Mi intención es abordar este tema siguiendo un camino que ya he recorrido en otras ocasiones (en especial para tratar cuestiones estéticas y epistemológicas) y que tiene como elemento central el concepto de representación. Palabras clave: Diderot - Encyclopédie - Ilustración - Representación

\section{Diderot's reflections in the article ENCYCLOPÉDIE.}

\section{Criticism and representation in the French dictionary}

\begin{abstract}
The aim of this paper is to offer an interpretation of some of Diderot's reflections in the article ENCYCLOPÉDIE, which are mostly related to the problem of the passage of time and its repercussions on the design of the work. In particular, I am interested in linking this problem to a more complex issue that is always present in our author's considerations: that of the critical power of the Encyclopédie and the way in which it could serve as a vehicle for Enlightenment interests. My intention is to approach this subject by following a path that I have already followed on other occasions (especially in the fields of aesthetics and epistemology) and which has the concept of representation as its central element.
\end{abstract}

Keywords: Diderot - Encyclopédie - Enlightenment - Representation

\footnotetext{
${ }^{1}$ Doctor en Filosofía (Universidad de Buenos Aires). Docente-Investigador del Instituto de Humanidades y Ciencias Sociales (IHUCSO) / Universidad Nacional del Litoral - CONICET. Ha realizado estudios de Doctorado y Posdoctorado con Becas del CONICET. Su campo de investigación es la Ilustración; en particular, se dedica al pensamiento de Denis Diderot, a la Enciclopedia francesa y a la Estética del s. XVIII. E-mail: estebanponce@hotmail.com.
} 


\section{Introducción}

Como se ha señalado en reiteradas ocasiones, la Encyclopédie puede ser considerada como la obra más representativa del movimiento ilustrado francés. Por su carácter colectivo - es decir, por la pluralidad de voces que colaboraron en el proyecto - y por las disciplinas y materias allí tratadas (pensemos sobre todo en el espacio dedicado a las artes mecánicas y las ilustraciones de los 11 volúmenes de láminas que acompañaban a los artículos), la obra se distinguió de las de sus predecesores de los siglos pasados. Además, como bien señala LecaTsiomis, a diferencia de los autores anteriores, desde Alstedius a Furetière, o del padre Souciet, del Dictionnaire de Trévoux, a Chambers, que habían sido esencialmente solitarios que recopilaban, copiaban, relacionaban saberes heterogéneos, productos de segunda mano, la Encyclopédie recurrió directamente a los eruditos, es decir, a los sabios vivos y no ya, como aquéllos, a la mera compilación libresca².

Entre los miles de artículos y textos que forman parte de la Encyclopédie, hay algunos que revisten un interés especial para el propósito de este trabajo. Se trata de aquellos escritos que, por su carácter reflexivo, nos brindan la posibilidad de comprender los diversos problemas a los que se enfrentaban los directores de la obra, como así también las soluciones que pensaron para llevar la empresa a buen puerto. En general, tales escritos pueden clasificarse como metadiscursivos, y el lugar que ocupan en el Diccionario es, podríamos decir, marginal en tanto no forman parte del contenido propiamente dicho, como sí lo hacen los artículos. Nos referimos, especialmente, al Prospecto elaborado por Diderot en 1750; al Discurso preliminar de d'Alembert, de 1751 (con la colaboración de Diderot), y a los diferentes Avertissements, aparecidos en los primeros siete volúmenes (1751-1757). Sin embargo, hay un texto que se destaca por ser, a la misma vez, artículo y metadiscurso: la entrada ENCYCLOPÉDIE, redactada por Diderot para el volumen V (1755).

En efecto, este artículo reúne varias características que lo vuelven un texto muy rico para el análisis. En primer lugar, porque Diderot lo redactó en una época en que sus escritos personales habían tomado ya una dirección que marcaría el rumbo de su obra hasta el final. Además, porque tiene una extensión considerable, se trata de uno de los artículos más largos de toda la Encyclopédie. También nos parece relevante que nuestro autor se exprese allí con una llamativa libertad (sobre todo teniendo en cuenta el examen del censor al que estaban sometidos los artículos previo a su publicación), revelando abiertamente algunos detalles del trabajo de edición y de evasión de los censores reales. Por otra parte, porque, por la fecha de su publicación, a diferencia del Prospecto o del Discurso preliminar, que proyectaban una obra que estaba todavía por hacerse - o que había sido recién iniciada -, el artículo se redacta a varios años del comienzo de la obra y esto le permite a Diderot hacer un balance sobre las expectativas, los logros y los defectos de una empresa ya en marcha. Asimismo, porque se trata de un texto clave para entender cómo pensaba Diderot el proyecto, cuáles fueron sus estrategias y cuáles eran las claves que solo él conocía para entender lo que pasaba en ese inmenso cúmulo de materiales (como señalan los editores asociados en una carta dirigida a

\footnotetext{
2 MARIE LECA-TSIOMIS (2014), “L'Encyclopédie: entre héritages et innovations”, en Qu'est-ce que l'Encyclopédie?, Édition Numérique Collaborative et CRitique de l'Encyclopédie, http:/ / enccre.academie.sciences.fr.
} 
d'Argenson con motivo de la encarcelación de Diderot) ${ }^{3}$. Finalmente, porque allí se encuentra el famoso pasaje donde Diderot confiesa el objetivo real y último del proyecto: "cambiar la forma común de pensar", sobre el que nos interesa hacer alguna observación.

En lo que sigue, vamos a poner a consideración una lectura que busca relacionar la cuestión del potencial crítico de la Encyclopédie con una serie de tópicos presentes en la obra personal de Diderot. Sugerimos que estos tópicos, cuyo elemento central está en el concepto de representación ${ }^{4}$, sirvieron a nuestro autor de fundamento teórico para pensar en la estrategia de dirección de la obra.

\section{El contexto en la obra de Diderot}

Antes de entrar en el análisis de algunas de las reflexiones de Diderot en el artículo ENCYCLOPÉDIE, será necesario realizar un breve rodeo, mediante el cual buscaremos señalar ciertos motivos de su producción personal que están allí presentes. Nos referimos a un conjunto de textos que Diderot viene trabajando, por lo menos, desde $1749^{5}$, y en los que pueden percibirse los primeros esbozos de una teoría que, en su desarrollo, intentará dar cuenta de la relación entre el sujeto y la naturaleza. Esta relación, como intentaremos mostrar, tiene dos instancias claramente distinguibles: por un lado, la experiencia (el complejo mecanismo de percepción que involucra, de un lado, la materialidad del cuerpo con todas sus afecciones, y del otro, la actividad racional implicada en el juicio del sujeto) y, por el otro, la representación (los modos en que damos a conocer esa experiencia - sea a nosotros mismos, sea a otros -, mediante la expresión).

Los escritos sobre los cuales nos detendremos brevemente son: la Carta sobre los ciegos para uso de los que ven (1749); la Carta sobre los sordomudos para uso de los que hablan y oyen (1751); Sobre la interpretación de la naturaleza (1753/4); y los artículos redactados para la Encyclopédie: BELLO (Vol. II, 1752, pp. 169b-181a), ECLECTISISMO (Vol. V, 1755, pp. 270a-293b) y GENIO (Fil. y Lit.) (Vol. VII, 1757, pp. 582a-584a).

\footnotetext{
${ }^{3}$ Cfr. la serie de cartas enviadas por los libreros editores a d'Argenson, apenas Diderot fuera encarcelado en Vincennes por la publicación de la Carta sobre los ciegos. Citamos aquí un extracto de la primera de esa serie (que luego tendrá otras tres con un incremento progresivo de argumentos que apuntaban a la excarcelación de Diderot): Lettre 24 de julio de 1749: "Nous prenons la liberté de nous mettre sous la protection de Votre Grandeur et de lui représenter les malheurs auxquels nous expose la détention de M. Diderot, conduit ce matin à Vincennes par ordre du Roi. C'est un homme de lettres d'un mérite et d'une probité reconnus ; nous l'avons chargé depuis près de cinq ans de l'édition d'un dictionnaire universel des sciences, des arts et métiers. Cet ouvrage qui nous coûtera au moins deux cent cinquante mille livres et pour lequel nous avons déjà avancé près de quatre-vingt mille livres était sur le point d'être annoncé au public. La détention de M. Diderot, le seul homme de lettres que n[ous] connaissions capable d'une aussi vaste entreprise et [qui] possède seul la clef de toute cette opération peut entraîner notre ruine (el subrayado es nuestro). Disponible en: https://encyclopedie.uchicago.edu/node/105. ${ }^{4}$ Intentaremos dar un sentido preciso a este término en el desarrollo de nuestro trabajo, pues no se trata de un concepto que Diderot utilice específicamente.

${ }^{5}$ Podríamos, sin embargo, sumar aquí textos anteriores a esta fecha que tocan parcialmente los temas a los que nos dedicaremos en este apartado: Elpaseo del escéptico, de 1747, donde se plantea, entre otras cosas, el problema de la salida de la filosofía de la clandestinidad, el paso de la esfera privada a la esfera pública (Cfr. nuestro: Les sectes philosophiques dans La promenade du sceptique, en La Lettre clandestine, $\mathrm{n}^{\circ} 23.2015$, pp. 279-300), y las Mémoires sur différents sujets des mathématiques, de 1748, donde comienza a perfilar la noción de relaciones (rapports) que será retomada como clave de su artículo BELLO.

${ }^{6}$ Como es sabido, el artículo GÉNIE es atribuido a Saint Lambert. Sin embargo, las ideas allí expresadas pueden considerarse compartidas por Diderot, pues el contenido del mismo puede ser reconstruido prácticamente en su totalidad a partir de fragmentos esparcidos en diferentes textos de la obra de nuestro autor.
} 
De la Carta sobre los ciegos nos parece relevante destacar dos tesis que, aunque por diferentes caminos, comienzan a delinear las condiciones de la experiencia: 1) que nuestras creencias, ideas, concepciones, e incluso, toda nuestra metafísica, están mediadas por las condiciones materiales de la experiencia. La falta de un sentido es aquí un claro ejemplo de ello: Saunderson, el matemático ciego, le dice al ministro religioso Holmes “¡Ay!, señor (...) dejad de lado ese hermoso espectáculo que no ha sido hecho para mí. He sido condenado a pasar mi vida entre tinieblas y vos me citáis prodigios que en absoluto entiendo y que sólo sirven de testimonio para vos y para quienes, como vos, pueden ver. Si queréis que crea en Dios, habéis de conseguir que lo toque"7; 2) que es preciso distinguir la sensación, de la percepción. En otras palabras, considerar separadamente la mera afección sensible, de la captación de sentido de aquello que nos afecta ${ }^{8}$. Esta cuestión, que requiere de toda una investigación sobre el uso de los símbolos, del lenguaje de cada uno de los sentidos, de los esquemas, de las formas, etc., está sugerida (aunque no resuelta) en la discusión que da Diderot sobre el problema de Molyneux.

La segunda tesis, la de la distinción entre la pasiva recepción de lo externo por medio de los sentidos y la actividad del sujeto que configura simbólicamente la experiencia, será retomada y desarrollada desde diversos aspectos en los años siguientes. Escritos casi simultáneamente, el artículo BELLO y la Carta sobre los sordomudos volverán a tratar el problema de la experiencia y su representación. En el artículo, Diderot discutirá el problema del juicio estético, ubicándose entre dos posiciones antagonistas. La crítica a estas perspectivas tiene su fundamento, precisamente, en el carácter inacabado de la noción de experiencia que defienden. El sentimentalismo (aquí representado por Hutcheson, pero también extensible a la tradición empirista y su concepción de la experiencia), supone un sujeto pasivo en la recepción de los datos que afectan a los sentidos - en el caso del juicio de gusto, al sentido interno de la belleza -, dejando de lado la participación activa del sujeto, presente, para Diderot, en la percepción de relaciones: "Es la indeterminación de esas relaciones, la facilidad para captarlas y el placer que acompaña a su percepción, lo que hizo suponer que lo bello era más una cuestión de sentimiento que de razón"”. Por otra parte, frente a las posiciones representadas por la tradición clásica, deudora del racionalismo cartesiano, que sostienen que habría una aprehensión intelectual de las reglas inmutables, eternas y absolutas de lo bello, Diderot reclamará que no logran dar cuenta del origen de las nociones que conforman aquellas reglas: orden, relación, simetría, etc., y afirmará que dichas nociones son adquiridas en la experiencia: "Y cualesquiera que sean las expresiones sublimes de las que nos servimos para designar las nociones abstractas de orden, proporción, relaciones y armonía, llamémoslas, si se quiere, eternas, originales, soberanas, reglas esenciales de lo bello, pasaron por nuestros sentidos para llegar a nuestro entendimiento"10. El asunto de las condiciones necesarias para la experiencia en la filosofía de Diderot requeriría un desarrollo que aquí no podemos ofrecer, pues nos desviaríamos de nuestro objetivo. Basten estas

\footnotetext{
${ }^{7}$ DIDEROT, Carta sobre los ciegos seguido de Carta sobre los sordomudos, p. 42.

${ }^{8}$ Como ha sido sugerido por David Funt, el origen de esta tesis estaría en una distinción análoga, aunque no idéntica, propuesta por Leibniz, en sus Principios de la naturaleza y de la gracia fundados en la razón. Cfr. "Diderot and the Esthetics of the Enlightenment", en Diderot Studies (1968), Vol. 11, p. 40 y ss.

${ }^{9}$ DIDEROT; D'ALEMBERT (eds.) (1751-1767), Encyclopédie ou Dictionnaire raisonné des sciences, des arts et des métiers, par une Société de Gens de Lettres. Paris : chez Briasson, David, Le Breton, Durand, Vol. II, p. 176b. (la traducción es nuestra).

${ }^{10}$ DIDEROT; D’ALEMBERT, Encyclopédie..., vol. II, p. 175b.
} 
mínimas consideraciones sobre el tema de la experiencia, para pasar a tratar el de la representación, cuyas líneas directrices se encuentran por primera vez formuladas en la Carta sobre los sordomudos.

Diderot comienza discutiendo allí el asunto de las inversiones gramaticales en las lenguas antiguas y modernas (un tema en boga, cuya resolución permitiría decidir qué lengua es la más apropiada para la correcta expresión del pensamiento). Pero rápidamente cambia el eje de la discusión, señalando que la cuestión está mal planteada, para introducir dos observaciones importantes: 1) que no hay un correlato ontológico entre la estructura gramatical del lenguaje y lo que llamamos realidad: "Poco a poco nos hemos acostumbrado a creer que dichos nombres [los sustantivos] representaban a seres reales: hemos mirado las cualidades sensibles como simples accidentes y hemos imaginado que el adjetivo estaba realmente subordinado al sustantivo, aunque el sustantivo no sea propiamente nada, y el adjetivo lo sea todo" ${ }^{\prime 1}$. Desde el punto de vista de Diderot este error es el resultado del peripatetismo escolástico, que ha otorgado realidad efectiva a conceptos que se construyen en el proceso de abstracción del pensamiento. Al mismo tiempo, es consecuencia de haber considerado al lenguaje discursivo como constitutivo de toda experiencia y haber supuesto que, en la afección sensible del cuerpo, existe un orden natural de ideas que se suceden como si estuvieran ya en el lenguaje. De aquí la necesidad de marcar un hiato entre la experiencia y su expresión. Precisamente, esta es la segunda tesis que nos interesa resaltar de ese texto: 2) que no existe un orden natural discursivo en la experiencia; que la discursividad en el pensamiento (que luego refleja el lenguaje) es ya un producto del análisis del contenido de lo que Diderot denomina el estado efectivo del alma. Un estado que existe como impresión total en un instante indivisible:

El estado del alma en un instante indivisible fue representado por una multitud de términos que la precisión del lenguaje exigía y que distribuyeron una impresión total en partes: y como esos términos se pronunciaban sucesivamente y sólo se entendían a medida que se pronunciaban, se tuvo tendencia a creer que las afecciones del alma que representaban tenían la misma sucesión; pero no es así. Una cosa es el estado de nuestra alma, otra cosa las cuentas que rendimos, bien a nosotros mismos, bien a los demás; una cosa la sensación total e instantánea de dicho estado; otra cosa la atención sucesiva y detallada que nos vemos forzados a dar para analizarla, manifestarla y hacernos oír. Nuestra alma es un cuadro viviente a partir del cual pintamos sin cesar: empleamos mucho tiempo en reproducirlo con fidelidad, pero existe entero y a la vez: el espíritu no avanza a pasos contados como la expresión. ${ }^{12}$

Más allá de lo que sigue en esta Carta, lo que nos interesa notar aquí es que estas primeras observaciones implicaban enfrentarse a un problema al que Diderot volvería una y otra vez en distintos momentos de su vida: el problema de la representación. En efecto, siendo el estado del alma (la experiencia afectiva) algo total y simultáneo, ¿cómo lograr su expresión

${ }^{11}$ DIDEROT, Carta sobre los ciegos seguido de Carta sobre los sordomudos, p. 84.

${ }^{12}$ DIDEROT, Carta sobre los ciegos seguido de Carta sobre los sordomudos, pp. 104-5. 
justa, su equivalente mediante una representación? ¿Cómo salvar esa distancia que se abre entre la experiencia y su expresión? Diderot muestra que, por distintas razones, tal cosa es imposible, aunque hay modos de aproximarse a un ideal en las artes: la expresión jeroglífica (propia del genio). Este tipo de expresión tiene la potencia de restituir en el receptor la simultaneidad del estado efectivo del alma que ha sido indefectiblemente analizado antes de darse en una representación. El trabajo de representación del artista consiste, precisamente, en valerse de los recursos de su arte para borrar las huellas de la composición. Diderot sugiere que deberían estudiarse las expresiones jeroglíficas de cada arte, puesto que todas las tienen, pero solo da una idea concreta de lo que sucede en la poesía:

Hay que distinguir, en todo discurso en general, el pensamiento y la expresión. Si el pensamiento está reproducido con claridad, pureza y precisión, es suficiente para la conversación familiar: a esas cualidades añadid la elección de los términos, con el número y la armonía del periodo, y tendréis el estilo que conviene al púlpito, pero todavía estaréis lejos de la poesía, sobre todo de la poesía que la oda y el poema épico despliegan en sus descripciones. Entonces, recorre el discurso del poeta un espíritu que mueve y vivifica todas las sílabas. ¿En qué consiste ese espíritu? A veces he sentido su presencia; pero todo cuanto sé de él es que es quien hace que las cosas sean dichas y representadas a la vez; que al mismo tiempo que el entendimiento las capta, el alma se conmueve, la imaginación las ve, y el oído las oye; y que el discurso ya no es solamente una concatenación de términos enérgicos que exponen el pensamiento con fuerza y nobleza, sino que también es un tejido de jeroglíficos puestos los unos sobre los otros, que la pintan. Podría decir en este sentido que toda poesía es emblemática. ${ }^{13}$

En términos generales, podemos decir que las expresiones jeroglíficas en las artes son obra del genio. Sin embargo, también su recepción exacta, la captación precisa del jeroglífico será privativa del genio: "Pero la inteligencia del emblema poético no le es dada a todo el mundo; hay que estar casi en situación de crearlo para sentirlo con firmeza (...) He aquí, señor, uno de esos problemas [el de la captación del emblema] que el genio poético resuelve sin proponérselo" ${ }^{14}$. Como podemos ver, en cuanto a la comprensión acabada de una representación en el ámbito de las artes, las condiciones establecidas por Diderot son muy exigentes. Sin embargo, hay comprensiones de sentido común que, si bien no llegan a sentir plenamente todos los elementos del jeroglífico, alcanzan para ser afectados por la unidad de sentido. En efecto, tal como lo señalará Diderot en su labor de crítico desarrollado en los Salones, la unidad será una de las condiciones mínimas que se exigen al artista para que su obra sea lograda ${ }^{15}$.

Ahora bien, la relación entre lo uno y lo múltiple, la configuración de una totalidad a partir de elementos, debe ser analizada atendiendo a las operaciones de las facultades del sujeto. En el siguiente apartado, buscaremos mostrara cómo podemos, a partir de este

\footnotetext{
${ }^{13}$ DIDEROT, Carta sobre los ciegos seguido de Carta sobre los sordomudos, pp. 110-11.

${ }^{14}$ DIDEROT, Carta sobre los ciegos seguido de Carta sobre los sordomudos, pp. 111-2.

${ }^{15}$ Con respecto a la necesidad de unidad en la obra de arte, cfr. el análisis de FRIED, El lugar del espectador. Estética orígenes de la pintura moderna, Caps. II y III.
} 
análisis, extender el alcance del concepto de representación más allá de los límites de la esfera de las artes.

\section{Representaciones en la ciencia}

Comencemos por constatar que, para Diderot, la ciencia es una imagen de la naturaleza ${ }^{16}$. Esta idea puede ser entendida, al menos, en dos sentidos: en primer lugar, que la ciencia refleja a la naturaleza, al modo de un espejo. Este sentido es el que Diderot tiene presente en la carta que citamos, modo habitual de concebir la relación naturaleza-ciencia en la época: "al igual que en la naturaleza no hay un fenómeno que podamos considerar el último, tampoco en la ciencia, que es una imagen de la naturaleza, hay ninguna proposición que podamos considerar la última" (subrayado nuestro). El segundo sentido, está teñido de un sano escepticismo que Diderot nunca abandonó en sus especulaciones y que adquiere el significado, ya no de un reflejo, sino de una representación. Aquí es donde el concepto de interpretación tiene un peso determinante, pues el hecho de que la naturaleza deba ser interpretada ${ }^{17}$, indica claramente la necesidad de recurrir a sistemas, esquemas, fórmulas, etc. que puedan representar por su mediación lo que de otro modo no podría ser comprendido. Ahora bien, ¿qué hay en común entre las representaciones de las artes y las de la ciencia? Ya hemos adelantado una posible respuesta: toda representación supone la elaboración de una unidad, una totalidad a partir de elementos.

En los escritos de época de Diderot, podemos observar que existe un paralelismo entre las formas de representación de las artes y de la ciencia. Si, como ya hemos advertido, atendemos a las operaciones que realizan las facultades en la construcción de representaciones, notaremos que no se trata simplemente de una analogía. Para nuestro propósito, la relación que existe entre los elementos que forman parte de las operaciones puede ser presentada, esquemáticamente, bajo dos aspectos: por un lado, aquello que corresponde a las representaciones. Aquí nos referimos, principalmente a la relación entre lo uno y lo múltiple. En la obra de arte, esta relación ha sido históricamente presentada de diversos modos, destacándose el binomio forma-contenido. Como sabemos, la forma será aquello que unifica o integra los elementos de la composición. También hemos visto que esta relación puede ser pensada, en el caso de Diderot, como unidad de sentido o "idea" que rige la composición, y que es anterior (temporal y causalmente) a la distribución de los elementos constitutivos. Pensemos, nuevamente, en cómo el artista debe trabajar la materia de su arte para que desaparezca, en la obra acabada, tanto su huella como la mera materialidad de los elementos.

La misma relación entre lo uno y lo múltiple está presente en la representación de la ciencia. En este ámbito, podemos incluso ver que la relación se reduplica a medida que la ciencia va adquiriendo mayor generalidad: lo elemental y múltiple, en una primera instancia, serían hechos o fenómenos de la naturaleza, que son unificados bajo una ley particular. El conjunto de las leyes particulares (aquí ahora ocupando el lugar de lo múltiple), debe ser unificado en una ciencia particular. Finalmente, las múltiples ciencias particulares, deben ser

${ }^{16}$ Cfr. la carta de Diderot a Sophie, del 21 de noviembre de 1762, Cartas a Sophie Volland (2010), Acantilado, Madrid, ed. de Laurent Versini, trad. de Nuria Petit, Acantilado, Barcelona, p. 324.

17 Nos referimos, claro está, a la decisión de Diderot de titular su obra sobre la metodología científica Interpretación de la naturaleza. 
coordinadas y unificadas en un sistema de la naturaleza, aspiración última de la ciencia en cuanto tal. Diderot trató explícitamente este problema en Sobre la interpretación de la naturaleza (volveremos a tratar más adelante este texto): "la independencia absoluta de un solo hecho es incompatible con la idea de totalidad; y sin la idea de totalidad, ya no hay filosofía" (XI), y más adelante, "[El] objeto más grande que la inteligencia humana puede proponerse es el sistema universal de la naturaleza (L) (subrayado nuestro)".

El segundo aspecto a considerar es el de las operaciones y las facultades que entran en juego en la producción y en la recepción de las representaciones. Podemos simplificar también los diversos modos en que operan las facultades aludiendo al par análisis-sintesis. Las facultades son, por supuesto, imaginación y entendimiento (o razón, sin más), respectivamente. Y las operaciones correspondientes, dependiendo del ámbito de aplicación, pueden ser ejemplificadas con el paso de lo simultáneo a lo discursivo y viceversa (tal como lo vimos en el caso del jeroglífico poético); el trabajo de descomposición-reunión, en el sentido clásico de la terminología empirista, que vale tanto para la composición artística como para la relaciones entre ideas, por el lado de la imaginación, y el lugar de síntesis que representa el entendimiento, en la medida en que unifica lo múltiple mediante la actividad judicativa.

Estos dos aspectos, apenas esbozados aquí, nos resultan interesantes porque sirven a Diderot como punto de partida para distinguir, tanto en la esfera de las artes como en la de la ciencia, dos posibles intervenciones. Nos referimos a las figuras contrapuestas de geniohombre de gusto, por un lado, y experimentador-especulador (o ecléctico, como veremos a continuación), por el otro. Veamos, para continuar, cómo estas tipologías aparecerán bajo distintos aspectos en el conjunto de obras que mencionamos anteriormente.

En varias ocasiones, Diderot traza una distinción clara entre las formas de operar del genio y las del hombre de gusto. En sus Salones es un tópico recurrente; también está marcada tal diferencia en el artículo GÉNIE; pero en ningún lado queda más patente que en la Carta sobre los sordomudos, cuando dice, respecto de un verso ${ }^{18}$, lo siguiente:

¡Todos exclaman, qué hermoso es! Pero quien mida el número de sílabas de un verso con los dedos, sentirá lo afortunado que es el poeta que tiene que pintar un soupir de que exista en su lengua una palabra cuya primera sílaba es sorda, la segunda tónica, y la última muda. Se lee: 'étend les bras', pero no se sospecha en absoluto la longitud y el cansancio de esos 'bras' al estar representados mediante ese monosílabo plural. Esos brazos extendidos caen tan suavemente con el primer hemistiquio del verso que casi nadie se da cuenta, como tampoco del movimiento del párpado en 'ferme l'oeil', y del paso imperceptible de la vigilia al sueño en la caída del segundo hemistiquio cierra los ojos y se duerme. El hombre de gusto observará sin duda que el poeta tiene que pintar cuatro acciones, y que su verso está dividido en cuatro miembros; que las dos últimas acciones están tan cercanas la una de la otra que apenas se distinguen intervalos entre ellas y que de los cuatro miembros

\footnotetext{
${ }^{18}$ El verso en cuestión es: "Soupire, étand les bras, ferme l'oeil, et s'endort" (Suspira, extiende los brazos, cierra los ojos, y se duerme. Boileau, Le lutrin).
} 
del verso, los dos últimos, unidos por una conjunción y por la rapidez de la prosodia del penúltimo, también son casi indivisibles; que cada una de estas acciones toma, de la duración total del verso, la cantidad que le conviene según su naturaleza, y que al encerrarlas a las cuatro en un solo verso, el poeta ha satisfecho la prontitud con la que tienen costumbre de sucederse. He aquí, señor, uno de esos problemas que el genio poético resuelve sin proponérselo (subrayado nuestro) (p. 111-2).

La explicación que da Diderot de la diferencia radical entre las actividades sintética y analítica que gobiernan las producciones del genio o del hombre de gusto es muy compleja, e implica vérselas con los posteriores desarrollos que el autor realiza en sus estudios sobre fisiología. No nos detendremos en ello ahora, pues solo nos interesa mostrar cómo estas mismas características se vuelven a dar cita en el ámbito de la ciencia. Ya en el artículo GÉNIE, está el reconocimiento de la presencia del genio en la filosofía, el único capaz de ofrecer la unidad que la multiplicidad de la experiencia no podrá nunca brindarnos. Diderot ya había hecho una incursión importante sobre este tema en Sobre la interpretación de la naturaleza, cuando se enfrenta al problema de la coordinación entre la recolección de hechos (experiencias y experimentos) destinados a acrecentar la evidencia empírica, a cargo de los laboriosos representantes de la filosofía experimental, por un lado, y los filósofos especuladores, encargados de combinar el material para dar con un sistema que dé unidad a los fenómenos, en forma de ley o sistema de la naturaleza, por el otro. Allí el "espíritu de adivinación" reviste las características del genio (I-XII). La idea de la genialidad en la filosofía también se expresa nítidamente en el siguiente pasaje: "Me imagino el amplio recinto de las ciencias como un gran terreno salpicado de lugares oscuros y de lugares iluminados. Nuestros trabajos deben proponerse, o bien extender los lugares iluminados, o bien multiplicar en el terreno los focos de luz. Lo uno corresponde al genio creador, lo otro a la sagacidad que perfecciona" (XIV).

Nuevamente, en el artículo ECLETISME, esta figura se repite bajo la forma del pensador ecléctico que se vale de los sistemas ofrecidos por la historia de la filosofía y que, en una especie de juego, combina sin cesar los elementos de los viejos edificios conceptuales que siguen siendo útiles (esto es, compatibles con los datos de la experiencia), para dar con un nuevo plano que los integre en un sistema:

El ecléctico no recoge verdades al azar; no las deja aisladas; menos aún se obstina por hacerlas encajar en algún plan determinado; cuando él ha examinado y admitido un principio, la proposición de la que ocupa inmediatamente después, o se une evidentemente con ese principio, o no se le une, o le es opuesta. En el primer caso, él la considera como verdadera; en el segundo, suspende el juicio hasta que nociones intermedias que separan la proposición que él examina del principio que ha admitido, le demuestren su unión o su oposición con ese principio; en el último caso, la rechaza como falsa. Éste es el método del ecléctico. Es así como él consigue formar un todo 
sólido, que es propiamente su obra, de un gran número de partes que ha recogido y que pertenecen a otros ${ }^{19}$.

Creemos que el concepto de representación, tal como lo hemos tratado hasta aquí, puede servirnos para pensar la ciencia como un sistema construido por elementos, con la finalidad de ser una imagen de la naturaleza. En efecto, así es como, desde nuestra perspectiva, lo entendía Diderot. Pero creemos que es posible extender aún más el alcance de dicho concepto para ver cómo funcionan las representaciones particulares en el contexto más amplio del saber de una época.

\section{La Encyclopédie y la representación del saber}

Aunque Diderot no utiliza el término 'representación' con un significado preciso, creo que podría ser útil ensayar una definición que nos permita avanzar con una interpretación sobre la tarea crítica de los filósofos del siglo XVIII, en general, y de Diderot, en particular. Se trata, entonces, de pensar las representaciones no solo como una producción individual (la expresión del estado de alma) o como un sistema general (tal como lo puede ofrecer una filosofía de la naturaleza), sino de extender su significado a aquellas formas de representación que son productos históricos de las sociedades, sedimentados en el tiempo. Las representaciones, así entendidas, nos permiten ampliar el horizonte hasta llegar a incluir, por ejemplo, a las instituciones, los valores, el derecho, la libertad, etc. Desde este punto de vista, el trabajo crítico de la razón ilustrada, en general, podría ser comprendido como la desarticulación de representaciones que, mediante el análisis de sus componentes, muestra o saca a la luz lo que de otro modo quedaría oculto.

Creemos que, en gran medida, mucho de lo que soñaba Diderot para el proyecto enciclopédico estaba enmarcado en esta tarea: en la posibilidad concreta de reunir a esa Sociedad de gentes de letras para llevar adelante la empresa crítica más ambiciosa del siglo. Pero, una vez hecha la crítica, este trabajo analítico con las representaciones que se quería denunciar, quedaba otra tarea no menos importante: la de la construcción de una nueva representación. Allí, el papel de Diderot como editor de la obra cobra todo su sentido: la nueva articulación, el trabajo de síntesis de los materiales que darían como resultado una nueva representación del saber, del hombre, de los valores ilustrados, etc.

El artículo ENCYCLOPÉDIE puede ser leído como una reflexión de Diderot acerca de la posibilidad, los obstáculos, los logros y los peligros de fracaso de una obra destinada a subvertir el orden de las cosas. Cabe preguntarse ¿por qué el tiempo aparece, en principio, como el gran enemigo de la empresa? Una respuesta posible, tal como señala Michel Malherbe, es la siguiente:

Toda enciclopedia tiene, en efecto, una función histórica: recoge el saber del pasado, lo entrega a los hombres de hoy y lo transmite a los hombres del mañana, para que sea incrementado. Ella misma es un objeto histórico; aunque a su modo, en tanto reunión de conocimientos dispersos, es un

${ }^{19}$ DIDEROT; D'ALEMBERT, Encyclopédie..., vol. V, p. 271a. 
momento privilegiado en la historia del conocimiento, no puede pretender representar la culminación del saber, y está condenada a envejecer con el tiempo ${ }^{20}$.

En efecto, Diderot aborda dos problemas fundamentales que podrían poner en riesgo el carácter representativo de la obra: el progreso en las ciencias y en las artes y la dinámica propia de las lenguas. Ambos problemas están relacionados con el transcurrir del tiempo y ese es el motivo por el que la Enciclopedia debe comenzarse y finalizarse en un período relativamente breve. De no alcanzar una realización rápida, la Enciclopedia acabaría siendo una obra del pasado. Este inconveniente puede ser atenuado mediante las estrategias de las que el mismo Diderot da cuenta en el artículo: el trabajo sobre los radicales lingüísticos, el orden enciclopédico que estructuraría el edificio de las ciencias, las referencias cruzadas que evitarían excesos y repeticiones, etc. Pero Diderot reconoce con cierta resignación que, tarde o temprano, el progreso de las ciencias y las artes harán el trabajo de Saturno, devorando a sus propios hijos. $\mathrm{Y}$, así las cosas, en cuanto al carácter representativo de la Encyclopédie en el ámbito del conocimiento, ésta no pasará de ser una imagen indefectiblemente temporal y transitoria de la naturaleza. De aquí que la posteridad podrá juzgar, a partir de su lectura, hasta dónde había llegado la humanidad en el siglo de la razón en materia de conocimientos, de una interpretación de la naturaleza en clave ilustrada.

Sin embargo, hay otro peligro al que Diderot hace referencia y es en el que me quiero detener aquí:

El momento más glorioso para una obra de esta naturaleza sería el que sucediera inmediatamente a una gran revolución que hubiera suspendido el progreso de las ciencias, interrumpido el trabajo de las artes, y sumido una parte de nuestro hemisferio de nuevo en la oscuridad. ¿Qué reconocimiento no le haría la generación que viniera después de estos tiempos difíciles a los hombres que los temían desde lejos, y que evitaron la devastación poniendo a resguardo el conocimiento de los siglos pasados? [...] La misma voz que recordará a los colaboradores de la Enciclopedia, tampoco olvidará hablar de las penas que soportaron los autores, y las desgracias que sufrieron; y el monumento que se les levantará tendrá muchas caras, donde se verán alternativamente honores concedidos a su memoria, y marcas de indignación ligadas a la memoria de sus enemigos. (Vol. V, p. 637)

Aunque la expresión que utiliza Diderot (revolución) es la misma que usó antes para describir el progreso de las artes y las ciencias, aquí tiene una connotación completamente diferente. Se trata de una revolución que detendrá el progreso y que no depende en absoluto del tiempo, sino de una imposición externa que tiene la fuerza suficiente para sumir en la

20 “Toute encyclopédie, en effet, a une fonction historique : elle recueille le savoir passé, elle le livre aux hommes d'aujourd'hui, elle le transmet aux hommes de demain pour qu'il soit augmenté. Elle-même est un objet historique ; même si à sa façon, en tant que rassemblement de connaissances éparses, elle est un moment privilégié dans l'histoire de la connaissance, elle ne peut prétendre représenter l'achèvement du savoir, et elle est condamnée à vieillir avec le temps” (MALHERBE, “L’Encyclopédie : histoire, système et tableau”, p. 45). 
oscuridad a una porción de la tierra. Diderot no aclara en este pasaje si se trata de un acontecimiento fortuito (natural, podríamos pensar) o si es una revolución intencionada. Sin embargo, la alusión a la posibilidad de anticiparse a la devastación que provocará y el remate del párrafo aludiendo a los enemigos de la Enciclopedia nos hace pensar en aquellas fuerzas que se han denominado como la Contrailustración. En otras palabras, creo que, de ser esta interpretación correcta, habría aquí un ejemplo claro de que la fe en el progreso por parte de los ilustrados no era para nada ingenua, como se ha querido establecer. Por el contrario, vemos en este pasaje la plena conciencia de que el progreso dependía, antes que de un necesario desarrollo de las capacidades humanas, de alcanzar las condiciones sociopolíticas que le dieran lugar. De aquí que el verdadero objetivo de la obra, la utilidad secreta, como decía Diderot, sea el de cambiar la forma común de pensar. Y quizá la primera condición para una sociedad que se quiere libre sea la de erradicar sus propios prejuicios. Las referencias cruzadas, desde esta perspectiva, son como un reguero de pólvora que irá dinamitando los prejuicios, a la vez que conducirá a las renovadas representaciones:

Toda vez que, por ejemplo, un prejuicio nacional mereciera respeto, correspondería a su artículo particular exponerlo respetuosamente, con todo su cortejo de verosimilitud y seducción; pero se derribaría el edificio de barro, se disiparía un vano montón de polvo remitiendo a los artículos en los que principios sólidos sirven de base para las verdades opuestas. Esta manera de desengañar a los hombres opera muy rápidamente sobre los buenos espíritus, y lo hace infaliblemente, sin ninguna consecuencia negativa y secretamente sobre todos los espíritus. Es el arte de deducir tácitamente las consecuencias más fuertes. Si estos reenvíos de confirmación y refutación se planean anticipadamente y se preparan con habilidad, darán a una Enciclopedia el carácter que debe tener un buen diccionario; ese carácter es cambiar la forma común de pensar (p. 643a subrayado nuestro).

Para ir finalizando. Es habitual entre los que se dedican al estudio de la Enciclopedia ver en este deseo de cambiar la forma común de pensar el llamado a una lectura ilustrada, y creo que es correcto, pero también puede pensarse que había otra vía, complementaria: aquella que silenciosamente operaría en el común de la gente a través de la modificación de aquellas representaciones que, en forma de prejuicios o creencias, eran funcionales al estado de cosas que se quería subvertir. Robert Darnton ${ }^{21}$, en su clásico ensayo, mostró cómo las sutiles modificaciones en el árbol del conocimiento ofrecían una nueva imagen o representación del saber en el siglo XVIII. Se trata de una de las representaciones más importantes que se pueden observar en la obra, pues como hemos visto, afecta al sistema total del saber representado. Pero hay otras, muchísimas otras que, aunque de menor alcance, funcionaban con la misma lógica. Citaré, para terminar, un solo ejemplo: el de las artes mecánicas.

En el artículo ARTE, redactado para el primer tomo, Diderot destina los primeros párrafos a desterrar un prejuicio, el de la superioridad de las artes liberales respecto de las

${ }^{21}$ DARNTON, La gran matanza de los gatos y otros episodios en la bistoria de la cultura francesa, pp. 192-215. 
artes mecánicas. Luego de analizar el origen de la división de las artes, en liberales y mecánicas, señala:

Esta distinción, aunque bien fundada, ha producido un mal efecto al degradar a gentes muy estimables y muy útiles, y favorecer en nosotros no sé qué pereza natural, que nos induce demasiado a creer que aplicarse constante y continuadamente a experiencias, objetos particulares, sensibles y materiales es ir en contra de la dignidad del espíritu humano. (...) Un prejuicio éste que tendía a llenar las ciudades de orgullosos razonadores y de contempladores inútiles y las campiñas de pequeños tiranos ignorantes, ociosos y desdeñosos. (...) Poned de un lado de la balanza las ventajas reales de las Ciencias más sublimes y de las Artes más honradas y en el otro las de las Artes mecánicas: veréis que el prestigio que se ha conferido a unas y el que se ha otorgado a las otras no se ha distribuido en relación justa de esas ventajas, y que se ha alabado mucho más a las personas ocupadas en hacer creer que éramos felices que a las ocupadas en hacer que lo fuéramos de hecho (Vol I, p. 714a).

Y luego de ofrecer un estudio sobre las particularidades de las artes mecánicas, dice:

Hagamos, pues, justicia a los artesanos como es debido. Las Artes liberales se han cantado a sí mismas suficientemente; ahora podrían emplear la voz que les quede para celebrar las Artes mecánicas. Corresponde a las Artes liberales sacar a las Artes mecánicas del envilecimiento en que las ha mantenido durante tanto tiempo el prejuicio; y a la protección de los reyes corresponde librarlas de la indigencia en la que aún languidecen. Los artistas se han creído despreciables porque se los ba despreciado.” (Vol I, p. 714a, subrayado nuestro).

Esta sorprendente reivindicación de las artes mecánicas, este cambio rotundo en la representación que de ellas se tenía, sería acompañado diez años más tarde con las impecables láminas de la Enciclopedia, que mostraban espléndidos talleres poblados de laboriosos artesanos. Sin duda, estas láminas de dibujos colaboraban, desde la potencia representativa de la imagen, en la dignificación de los oficios (Vol I, p. 717a).

\section{Referencias bibliográficas}

DIDEROT, D. ; d'ALEMBERT, J. (eds.). Encyclopédie ou Dictionnaire raisonné des sciences, des arts et des métiers, par une Société de Gens de Lettres. Paris: chez Briasson, David, Le Breton, Durand, 1751-1772.

DIDEROT, Denis. Carta sobre los ciegos seguido de Carta sobre los sordomudos. Trad. de J. Escobar. Valencia: Fundación Once y Pre-textos, 2002.

Investigaciones filosóficas sobre el origen y la naturaleza de lo bello. Trad. de F. Calvo Serraller. Madrid: Sarpe, 1984. 
Cartas a Sophie Volland. Acantilado, Madrid, ed. de Laurent Versini, trad. de Nuria Petit. Barcelona: Acantilado, 2010.

DARNTON, Robert. La gran matanza de los gatos y otros episodios en la historia de la cultura francesa. Trad. C. Valdéz, 2da. ed. (2000). México: FCE, 1987.

FRIED, Michael. El lugar del espectador. Estética orígenes de la pintura moderna. Colección La balsa de la Medusa. Madrid: Machado libros, 2000.

FUNT, David. "Diderot and the Esthetics of the Enlightenment". In: Diderot Studies, Vol. 11. Genève: Droz, 1968.

MALHERBE, Michel. "L'Encyclopédie : histoire, système et tableau". In: Groult, Martine (Dir), L’Encyclopédie ou la création de disciplines. Paris: CNRS, 2003.

LECA-TSIOMIS, Marie. "L'Encyclopédie : entre héritages et innovations". In: Qu'est-ce que l'Encyclopédie? Édition Numérique Collaborative et CRitique de l'Encyclopédie, 2014. 